Groothuis, P.A. and Miller, G. (1994) Locating Hazardous Waste Facilities: The Influence of NIMBY Beliefs, American Journal of Economics and Sociology, 53(3): 335 (July 1994). Published by Blackwell (ISSN: 0002-9246).

\title{
Locating hazardous waste facilities: the influence of NIMBY beliefs
}

Peter A. Groothuis and Gail Miller

\begin{abstract}
The 'Not-In-My-Backyard' (NIMBY) syndrome is analyzed in economic decision making. Belief statements that reflect specific NIMBY concerns are subjected to factor analysis and the structure reveals two dimensions: tolerance and avoidance. Tolerance reflects an acceptance of rational economic arguments regarding the siting of a hazardous waste facility and avoidance reflects a more personal fear-of-consequences. Analysis identifies demographic characteristics of individuals likely to exhibit these two beliefs. These beliefs also are shown to influence the acceptance of a hazardous waste disposal facility in ones neighborhood when compensation is offered.
\end{abstract}




\section{Introduction}

THE NEGATIVE REACTION to plans regarding the siting of hazardous waste disposal facilities is now well known. The Not-In-My-Backyard (NIMBY) syndrome has been documented by a growing stream of literature (O'Hare 1977; Peelle and Ellis, 1987; Inhabler 1992). Readers need only watch the evening news, or read a local paper to be reminded that protests accompany almost any siting plans for a variety of hazardous waste facilities in all parts of the country.

While the NIMBY syndrome is well established as a cognitive construct in the literature, the determinants and structure of such feelings are not well understood. The construct is usually assumed and researchers then examine its stability in the face of moderating variables. An example of this is the review by Peelle and Ellis (1987) that concluded with the call for the development of an analytic framework to evaluate the effectiveness of different incentives.

In research on influencing the acceptance of a facility viewed as noxious, compensation has become a recurring theme (O'Hare, 1977; Inhabler, 1992). To measure the compensation necessary to influence the acceptance of a siting economists have utilized the contingent valuation (CV) method. The CV method uses surveys to elicit peoples' preferences for nonmarket goods and changes in non-market good quality. (See Mitchell and Carson 1989). Studies that employ the CV methodology for the siting of hazardous waste facilities deal primarily with the incentive effect of compensation and do not explore the antecedent beliefs that respondents may have regarding the legitimacy and logic of providing the waste facility.

Beliefs provide information about feelings toward certain objects or concepts. The literature on consumer choice is rich with models that explore the measurement of beliefs as an antecedent of behavioral intentions. Among these models the evaluation of concepts utilizing a measure of feeling is regarded as a core activity (Day 1972). While the link between beliefs and actual behavior remains a topic of research and modeling, the basic feelings towards some object or concept remain as an initial measurable construct in models regarding behavior (Ryan 1982).

Incorporating the traditional CV technique with measures of beliefs furthers understanding of the choice process. The CV scenario is extended by exploring the belief structure of the NIMBY syndrome through factor analysis and by testing the role of beliefs, as measured by factor scores, in conjunction with offers of compensation. Data obtained from a mail survey shows that two primary beliefs underlie the NIMBY syndrome: tolerance and avoidance. Demographic information indicates who is likely to exhibit the beliefs. The factor scores reflecting the two beliefs are used as explanatory variables for accepting a hazardous waste disposal facility when compensation is offered. The conclusion suggests policy implications. 


\section{Contingent Valuation and the NIMBY Syndrome}

ECONOMISTS THEORIZE that the NIMBY syndrome leads to inefficient allocation of resources because the external monetary and psychological costs of a noxious facility are borne locally by the neighborhood surrounding the facility, while the benefits of a noxious facility are distributed globally throughout the economy (O'Hare 1977, Kunreuther et al 1987). To solve the problem of inefficiency and to locate a noxious facility, those that receive the benefits must compensate the neighborhood around the site for bearing the external cost of the facility (O'Hare 1977 and Kunreuther et al 1987).

Recent studies have pursued two approaches: (1) identify the amount of compensation necessary for the affected neighborhood and (2) identify the perceived risk of exposure from the facility rather than the amount of compensation necessary to site a hazardous waste facility. Following the first approach Smith and Desvousges (1986) use the CV method coupled with the hedonic price of housing technique. Here they measure the willingness of individuals to move into locations with hazardous waste facilities as neighbors. Roberts et al (1991) also use a CV survey to measure the willingness to pay to avoid a municipal waste disposal facility. Reflective of the second approach, Kunreuther and Easterling (1990) find that individuals are more concerned with potential risk of a low level nuclear waste facility than the level of compensation. Inhabler (1992) combines both approaches and states that the siting of a facility must be treated like a geometric proof by meeting both necessary and sufficient conditions. He states that the necessary condition is providing information to the public on the hazards of the facility. The sufficient condition, he argues, is providing appropriate economic incentives in the form of compensation to the individuals in the affected area. He argues further that if both conditions are met, then the facility can be sited.

While both the Inhabler (1992) and the Kunreuther Easterling (1990) studies allude to an avoidance stance, no study identifies an underlying dimension of tolerance in reaction to noxious facilities. The only other study that explicitly identifies a belief-incentive connection in CV analysis is Whitehead and Thompson (1993) where they look at underling motives in environmental preservation. No CV studies, however, have focused explicitly on beliefs in the context of a siting decision.

\section{III}

\section{The Survey}

BELIEFS CAN BE MEASURED and behavioral intentions can be obtained using mail survey techniques (Dillman 1978). Beliefs are measured using a five point Likert scale on the level of agreement to various attitudinal statements. Behavioral intentions are measured posing the respondent with hypothetical situations and markets following a model demonstrated by Mitchell and Carson (1989). 
Implementation of the $\mathrm{CV}$ technique requires a description of the amenity and a behavioral question. This study employs a willingness to accept (WTA) CV question where respondents are offered a take-it-or-leave-it situation. The dichotomous choice framework was chosen because of the potential for strategic behavior associated with open ended WTA measures. Mitchell and Carson (1989) state that respondents faced with an open ended WTA question respond with 'I want the most you will pay.' This biases WTA measures upwards.

The WTA question here, framed using a referendum election, was stated as follows:

Suppose the State proposes to locate the hazardous waste landfill in your county. In return the State proposes to compensate people by reducing State income taxes by \$A per family in your county per year. Would you be willing to accept this proposal?

\section{YES 2. NO 3. DON'T KNOW}

In the survey \$A consisted of five amounts: \$100, \$500, \$1000, \$1500 and \$2000 with only one amount randomly indicated on each survey instrument. These amounts were chosen from a preliminary study using an open ended WTA question. Follow up questions were used to eliminate protest responses.

The CV survey, conducted in the Spring of 1992, questioned residents of Lawrence County. Located forty miles north of Pittsburgh, Lawrence County is a Western Pennsylvania area with a population of 90,000, few population centers, and a declining industrial base. By virtue of its rural nature and proximity to major industrial centers, it has been targeted many times as a potential site for a hazardous waste disposal facility.

The survey was based on the Dillman (1978) total design method. The procedure consisted of one primary mailing, a post card reminder, and one replacement instrument. The total number of surveys returned was 345 (a response rate was 43 percent). Given the response rate, a potential for nonresponse and sample selection bias is present. (See Whitehead 1990 and Whitehead, Groothuis, and Blomquist 1993.) No tests, however, were performed to detect for either nonresponse or sample selection bias. Therefore the empirical results are suggestive rather than definitive.

Independent variables in this study, were defined as follows. Offer is the amount of money offered in tax reduction that ranged randomly from \$100 to \$2000. Income is annual household income with twenty-three missing values imputed using a wage equation. Age is the respondent's age with any missing values imputed with the mean age. Away is the number of years a respondent lived outside of Lawrence County, Pennsylvania. Children is the number of people under 18 years of age living in the respondent's household. Education is the years of the respondent's education with missing values imputed with the mean level of education.

The dependent variable used in the study was Choice which is a qualitative dependent variable equal to one if an individual responded YES to the CV question and zero if the individual responded NO. All DON'T KNOW responses were coded as YES because this indicates the respondent is considering accepting the proposal but is ambivalent. 
In Table 1 the means of the variables are reported. The demographic means reflect an aging population (a mean age of 52) with a long attachment to the area. The education level is close to the national average at 13.6 years. The demographics reflect a rural, small town setting such as most hazardous waste disposal firms target for siting their facilities.

Table 1

Demographic

Means Standard

Variables

Deviations

Choice

offer

Income

Age

Away

$\odot .46$

0.50

1,006

659.41

$30,512 \quad 15,985$

$52.3 \quad 15.8$

$11.0 \quad 15.8$

Children

0.57

0.93

Education

13.6

2.36

\section{IV}

\section{Statements of Beliefs}

EIGHT STATEMENTS were posed to respondents asking for agreement measured on a fivepoint Likert scale. The statements attempt to assess feelings about waste issues, and reflect some of the arguments that are made by proponents (e.g. job creation), and by opponents of such facilities (e.g. harmful to health, an eyesore). The full statements of beliefs are in the Appendix.

Table 2 lists the statements and reports the percentage of responses for each level of the scale. Statements were anchored by the words "Agree" and "Disagree" at polar ends of the five point scale. Agreement to a statement is reflected by a low value and disagreement with a high value.

There is very strong agreement with two statements that affect a respondent personally. The first addresses the value of property and the second, the impact on the health of people living near a facility. Seventy-eight percent of the respondents agreed that property value and forty-six percent agreed that health would be adversely affected by siting a waste facility nearby. Respondents also felt that state government should pass laws to keep out-of-state waste from entering, a specific action that has been ruled in violation of interstate commerce laws. To an extent, this statement may reflect a "don't dump on me" attitude engendered by stories of large urban areas desperate for landfill space.

Further, respondents are somewhat willing to accept the fact that waste facilities will create jobs and provide some tax revenues, but agreement with this statement is certainly not strong. Respondents are mostly unwilling to accept such facilities even when they know that they are responsible for generating some of the waste involved. 
Table 2

Statements of Beliefs(1)

Agree Disagree

$\begin{array}{lccccc}\text { LABELS } & 1 & 2 & 3 & 4 & 5 \\ & & & & & \\ \text { SENSITIVE } & 15.9 \% & 12.2 \% & 10.4 \% & 17.7 \% & 43.8 \% \\ \text { LAWS } & 78.6 & 6.6 & 5.5 & 3.7 & 5.7 \\ \text { SPACE } & 38.8 & 16.2 & 22.1 & 7.6 & 15.3 \\ \text { VALUES } & 72.3 & 16.1 & 7.8 & 2.6 & 1.2 \\ \text { AREA } & 15.8 & 14.9 & 28.9 & 14.0 & 26.3 \\ \text { EYESORE } & 16.9 & 19.0 & 23.0 & 14.3 & 26.8 \\ \text { HARMFUL } & 46.4 & 13.5 & 23.9 & 11.2 & 4.9 \\ \text { JOBS } & 26.7 & 20.1 & 26.5 & 12.8 & 14.0\end{array}$

1 Complete Statements of Beliefs in Appendix

The peaks of the frequencies of responses suggests the existence of a NIMBY-avoidance attitude. Only the last statement on jobs reflected a response that wasn't an "anti-facility" concept. The distribution of responses, however, indicates that it is likely to include some expression of what could be considered a "pro-facility" attitude.

\section{V}

\section{Factor Analysis on Beliefs}

FACTOR ANALYTIC TECHNIQUES were employed with the purpose of defining more fundamental constructs that summarize the original set. R-type factor analysis using orthogonal rotation, revealed the factor structure and permitted the computation of factor scores for each respondent that becomes data for demographic analysis. The principal component analysis (using SPSS-X) employed varimax rotation. Two factors emerged from the analysis, with four item "Loadings" on each factor. Table 3 gives the rotated factor loadings.

Loading heavily on the first factor are the items labeled Sensitive, Area, Eyesore and Jobs. Loading on the second factor are the items labeled Laws, Space, Value, and Harmful. Only one item, Harmful (to health), exhibited some ambiguity as to its best loading while the other loadings are quite crisp. The cumulative variance explained by the two factors is $50.4 \%$. The eigenvalues for the two factors are 2.68 and 1.35 respectively with no others greater than 1.0. A three factor extraction revealed an eigenvalue of .84 for the third factor and a more ambiguous structure of factor loadings. Also, the scree plot indicated that a two factor extraction is appropriate (Kim and Mueller 1978). 
Table 3

Rotated Factor Loadings of NIMBY Attitudes

Label

SENSITIVE

LAWS

SPACE

VALUES

AREA

EYESORE

HARMFUL

JOBS
Tolerance

$$
.68\left({ }^{*}\right)
$$

$-.14$

.18

$-.17$

$.73\left({ }^{*}\right)$

$.69\left({ }^{*}\right)$

$-.55$

$.69\left({ }^{*}\right)$
Avoidance

$$
\begin{aligned}
& .09 \\
& .65\left(^{*}\right) \\
& .69\left(^{*}\right) \\
& .68\left(^{*}\right) \\
& -.11 \\
& -.06 \\
& .56\left(^{*}\right) \\
& .00
\end{aligned}
$$

Varimax rotation: * Indicates factors loading heaviest on each belief measure

The factor accounting for the most variance, 33.5\%, seems to address a dimension that includes the statements that suggest reason, or a degree of tolerance, regarding the siting dilemma. The statements labeled Sensitive, Area, Eyesore, and Jobs all address an underlying construct that is identified as Tolerance.

The second factor, accounting for an additional $17 \%$ of the variance addresses the fear and negative consequence dimension that is commonly associated with the NIMBY posture. Statements labeled in Table 2 as Laws, West, Value, and Harmful are expressions of fearful consequences or take-it-elsewhere sentiments. This factor is identified as Avoidance. The presence of this second factor comes as no surprise, however, the tolerance dimension raises the possibility that attitudes can be influenced by rational argument.

It should be noted that Tolerance and Avoidance factors are not reverse meanings of the same belief, but are separate beliefs. Individuals can exhibit both tolerance and avoidance, just one of the beliefs, or neither belief. The factor scores range from low values reflecting high levels of agreement to the various belief statements to high values reflecting disagreement to the belief statements. It should be further noted that the factors are a product of the inclusion of questions in the original questionnaire, but the analysis demonstrates that a generalized NIMBY response did not act as a halo that dismissed consideration of statements that give a rationale for acceptance of waste facilities in a person's locale.

\section{VI}

\section{Demographic Explanation of NIMBY Beliefs}

DEMOGRAPHIC ATTRIBUTES can be used to identify individuals who exhibit a level of tolerance as well as those who take an avoidance stance. Table 4 reports the ordinary least squares (OLS) regression results.

Column one provides the results of the Tolerance specification. The results show that high income and older respondents show greater tolerance of hazardous waste disposal facilities. The 
income variable supports the notion that higher income individuals tend to be more conservative with a pro-business stance. All other explanatory variables are insignificant.

Column two provides the results of the Avoidance specification that shows that older individuals as well as individuals with children take a more reactive stance. Both coefficients support the Viscusi and Moore (1989) notion that health concerns matter in a siting decision. Viscusi and Moore (1989) argue that children and older adults are more susceptible to environmental hazards prompting respondents to be more careful and express an avoidance stance. The results further show that individuals of high income and individuals who lived part of their life elsewhere\$before moving to Lawrence County are less likely to exhibit an avoidance stance. The coefficient on the Away variable indicates that individual with long attachments to a neighborhood have a higher avoidance stance. This supports the notion that individuals with longer attachments to a neighborhood have higher costs of moving to a new area, and thus tend to be more concerned about a deterioration in neighborhood quality. It also supports the notion that newcomers who are not likely to stay long have little concern for the welfare of the community.

Table 4

OLS Regressions of NIMBY Beliefs

(t-statistics in parentheses)

$\begin{array}{lcc}\text { Label } & \text { Tolerance } & \text { Avoidance } \\ \text { Constant } & .734 & .262 \\ \text { Income } & (1.67) & (0.59) \\ & -.162 & .095 \\ \text { Education } & (3.87) & (2.26) \\ \text { Age } & .010 & .013 \\ & (0.36) & (0.47) \\ \text { Away } & -.007 & -.007 \\ \text { Children } & (1.82) & .010 \\ & .0 \odot \odot 2 & (2.95) \\ \text { R2 } & (0.06) & -.118 \\ \text { Sample Size } & .065 & (1.65) \\ & (0.91) & .07 \\ & .07 & 321\end{array}$

The results indicate that higher income leads to more tolerance and less avoidance, while increases in age leads to more tolerance and more avoidance. The income results in both belief regressions support the notion that higher income respondents believe they have more control over life decisions (Bonjean and Grimes 1974).

\section{VII}

\section{Attitudes and Compensation}

PROBIT ANALYSIS Of the dichotomous choice question was used to analyze behavioral intentions. The results are reported in Table 5. Two specifications are reported: one includes both 
the factor scores with demographic information the other includes all variables except the factor scores.

The results of the specification incorporating the two factor scores shows that the more tolerant the individual, the more likely they will accept the compensation proposal. The results also indicate that the higher the level of avoidance, the less likely the individual will accept the offer. Both results support the postulate that underlying beliefs are important in the decision, and the types of belief is consistent with acceptance of an offer.

This study also finds that income has a negative and significant influence on accepting an offer when factors scores are included, and income is insignificant when belief factor scores are excluded. This indicates that the specification that excludes the belief measures may be misspecified where income serves as a proxy for a high degree of tolerance and a low avoidance stance. The negative and significant coefficient on income supports the hypothesis that individuals with high income are willing to pay more for neighborhood quality.

\begin{tabular}{|c|c|c|}
\hline Dependent Variable & Choice & Choice \\
\hline Constant & $\begin{array}{l}1.520 \\
(1.51)\end{array}$ & $\begin{array}{c}.785 \\
(0.80)\end{array}$ \\
\hline offer & $\begin{array}{c}.054 \\
(2.69)\end{array}$ & $\begin{array}{c}.053 \\
(2.83)\end{array}$ \\
\hline Tolerance & $\begin{array}{r}-1.115 \\
(6.87)\end{array}$ & --- \\
\hline Avoidance & $\begin{array}{c}.327 \\
(2.41)\end{array}$ & -- \\
\hline Income & $\begin{array}{l}-.313 \\
(2.85)\end{array}$ & $\begin{array}{c}.006 \\
(0.67)\end{array}$ \\
\hline Education & $\begin{array}{l}-.015 \\
(0.22)\end{array}$ & $\begin{array}{c}035 \\
(0.57)\end{array}$ \\
\hline Age & $\begin{array}{l}-.025 \\
(2.32)\end{array}$ & $\begin{array}{l}-.016 \\
(1.67)\end{array}$ \\
\hline Away & $\begin{array}{c}.0 \odot 4 \\
(\odot .5 \odot)\end{array}$ & $\begin{array}{c}.006 \\
(0.87)\end{array}$ \\
\hline Children & $\begin{array}{l}-.074 \\
(0.43)\end{array}$ & $\begin{array}{l}-.152 \\
(0.99)\end{array}$ \\
\hline Log-Likelihood & -172.28 & -205.09 \\
\hline Sample Size & 321 & 321 \\
\hline
\end{tabular}

This study finds that with income there are two separate effects. First, as income rises, individuals view that they have a greater control of their lives, which is reflected in a more tolerant and a less avoidance belief. Both increase the likelihood of accepting the offer. Second, as income rises individuals prefer greater neighborhood quality, which lowers the likelihood of accepting an offer. Excluding the belief measures causes an upwards bias on the income coefficient. 
In both specifications, the offer of compensation is positive and significant, while age is negative and significant. The positive sign on the coefficient on offer supports the hypothesis that compensation is important in a siting decision. While compensation is necessary in the siting process, other aspects are also important. The negative coefficient on age further supports Viscusi and Moore (1989) postulate that health concerns are important in a siting decision. All other variables are insignificant.

The results of the CV analysis supports the postulate that beliefs are important in understanding behavioral intentions. Excluding the role of beliefs in the siting decision and concentrating only on compensation limits the analysis. A broader focus that includes compensation and beliefs as conditions for a siting decision is a more fruitful path to pursue.

\section{VIII}

\section{Conclusion and PoBcy Implications}

THE BELIEF-BEHAVIOR connection is important to the understanding of a siting decision. Compensation plays a major role but underlying beliefs cannot be ignored. Our analysis finds that two primary beliefs underlie the NIMBY syndrome: Tolerance and Avoidance. The avoidance belief is well reflected in the literature, while the tolerance belief has been ignored in the past. It may be that individuals with a strong avoidance belief are vocal in a siting decision, while individuals with a more tolerance belief are quiet in a siting decision.

This study also finds that it is important to include beliefs in a CV analysis. Excluding beliefs leads to omitted variable bias and ignores an important component of decision making. By identifying which individuals are more likely to exhibit a greater level of tolerance and those who take a more avoidance stance, policy-makers can focus attention on influencing these underlying beliefs. The awareness that beliefs are important can lead policy makers in ways that focusing on compensation alone ignores. Through open forums, education, and advertising, the tolerance belief can be nurtured, then the siting decision can be better understood and an efficient and equitable solution found. 


\section{APPENDIX}

The statements of beliefs on the questionnaire were as follows:

SENSITIVE, "People get unnecessarily sensitive over the location of hazardous waste disposal facilities."

LAWS, "Pennsylvania should pass laws to prevent out-of-state waste from entering Pennsylvania."

SPACE, "The Federal Government should make space available for waste disposal facilities on sparsely settled land in the Western US."

VALUES, "Hazardous waste disposal facilities reduce property values for owners that are within several miles of the facility."

AREA, "Since every person contributes waste, some of it hazardous, people should allow processing facilities in their area."

EYESORE, "Waste facilities do not create an eyesore anymore than other industrial facilities."

HARMFUL, "Hazardous waste facilities will be harmful to the health of people who live nearby."

JOBS, "Waste facilities create jobs and an additional tax base for local communities."

\section{REFERENCES}

Bonjean, Charles and Micheal Grimes. "Community Power: Issues and Findings," Social Stratification: A Reader, New York: Harper 1974.

Day, George S. "Theories of Attitude Structure and Change" Consumer Behavior: Theoretical Sources. Englewood Cliffs, Prentice (1972) 303-53.

Dillman, Don A. Mail and Telephone Surveys: The Total Design Method. New York: John Wiley \& Sons, 1978.

Hair, Joseph F. Jr., Rolph E. Anderson and Ronald L Tatham. Multivariate Data Analysis, New York: MacMillan, 1987.

Inhabler, Herbert "Of NIMBYs, LULUs, and NIMTOOs," The Public Interest, Spring 1992, No. 107, 52-64. 
Kim, Jae-On and Charles W. Mueller "Factor Analysis: Statistical Methods and Practical Issues," Series: Quantitative Applications in the Social Sciences, Beverly Hills: Sage 141978.

Kunreuther, Howard, Paul Kleindofer and Peter J. Knez. "A Compensation Mechanism for Siting Noxious Facilities: Theory and Experimental Design," Journal of Environmental Economics and Management, 14 (1987): 371-83.

-----, and Douglas Easterling. "Are Risk-Benefit Tradeoffs Possible in Siting Hazardous Facilities," American Economic Review: Papers and Proceedings, 80:2, (1990): 252-56.

Mitchell, Robert and Richard T. Carson Using Surveys to Value Public Goods: The Contingent Valuation Method, Washington DC: Resources for the Future, 1989.

O'Hare, Micheal "'Not on my Block You Don't': Facility Siting and the Strategic Importance of Compensation, Public Policy 25:4, (Fall 1977): 407-58.

Peelle, Elizabeth and Richard Ellis "Beyond the 'Not-in-My-Backyard' Impasse," Forum for Applied Research and Public Policy (Fall 1987): 68-77.

Roberts, Roland K., Peggy V. Douglas and William M. Park "Estimating External Costs of Municipal Landfill Siting Through Contingent Valuation Analysis: A Case Study," Southern Journal of Agricultural Economics (1991): 155-65.

Smith, V. Kerry and William H. Desvousges. "The Value of Avoiding a LULU: Hazardous Waste Disposal Sites," Review of Economics and Statistics 68 (1986): 293-99.

Smith V. Kerry. "Valuing Amenity Resources Under Uncertainty: A Skeptical View of Recent Resolutions," Journal of Environmental Economics and Management 19 (1990): 123-46.

Viscusi, W. Kip and Michael J. Moore. "Rates of Time Preference and Valuation of the Duration of Life," Journal of Public Economics 38 (1989): 297-317.

Whitehead, John C. "Environmental Interest Group Behavior and Self-Selection in Contingent Valuation Mail Surveys," Growth and Change 221 (1991): 10-21.

-----, Peter A. Groothuis, and Glenn C. Blomquist "Testing for Nonresponse and SampleSelection Bias in Contingent Valuation: Analysis of a Combination Phone/Mail Survey," Economic Letters 41 (1993): 215-20.

-----, and Carol Y. Thompson "Environmental Preservation Demand: Altruistic, Bequest, and intrinsic motives," American Journal of Economics and Sociology 52:1 (1992) 19-30. 